\title{
Wiederholung des Versuchs von Gscheidlen zur Darstellung von Schwefelcyanblei aus Menschenharn.
}

Von

J. L. W. Thudiehum in London.

Obwohl aus den von mir in einer frühern Abhandlung angegebenen Eigenschaften des Schwefelcyanblei's mit Sicherheit hervorgeht, dass es auf dem von Gscheidlen eingeschlagenen Wege nur erhalten werden könnte, wenn davon mehr als drei Gramm in jedem Liter Harnextract enthalten wären, so hielt ich es doch für gerathen, den auf S. 405, Band 14 dieses Archivs beschriebenen Versuch zu wiederholen, um ein Urtheil darüber zu erhalten, was Gscheidlen wohl gefunden haben könnte. Ich fällte aus $17^{1 / 4}$ Liter Harn von drei gesunden Männern die Phosphor- und Schwefelsäure durch heisses konzentrirtes Barytwasser, verdampfte das Filtrat zum Syrup, und liess krystallisiren. Der abgegossene Syrup wurde mit Alkohol ausgezogen und gab viel kryptophansauren Baryt, der mit Bleizucker und Alkohol nach der von mir beschriebenen Weise behandelt, 20.4 Gramm weisses, nach dem Trocknen hörnig durchscheinendes kryptophansaures Blei lieferte. Dex Salzkuchen wurde für sich mit Alkohol extrahirt, und damit im Mörser sorgfältig durchgerieben und in einer verschlossenen Flasche durchgeschüttelt. Ich destillirte nun den Alkohol von den Extracten ab, und löste den Rückstand in Wasser. $\mathrm{Zu}$ dieser Lösung setzte ich Kalkmilch aus gebranntem weissem Marmor, und filtrirte. Ich konnte aber nicht beobachten, was Gscheidlen angibt, nämlich dass durch diese Operation der grösste Theil der Farbstoffe gefällt wurde. Im Gegentheil, das Filtrat war dunkel gelbroth gefärbt, und nicht nur schwach gelb wie Gscheidlen von seinem Filtrat berichtet. Ich engte abermals zum Syrup ein, wobei sich viel kohlensaurer Kalk, gemischt mit Uromelanin- und Urogittin-Kalk absetzte und behandelte das Filtrat abermals mit viel absolutem Alkohol. Alles löste sich, so dass ich die Behandlung mit Kalk sowohl, als die zweite Alkoholbehandlung für vollständig nutzlos ansehen musste. Ich destillirte den Alkohol abermals ab und brachte die Lösung auf 
das Volum eines Liters. Sie wurde nun in vierzig Portionen jede mit der nöthigen Menge Bleizucker versetzt und rasch abfiltrirt. Dabei hegte ich zwar nicht die Besorgniss von Gscheidlen, dass das Schwefelcyanblei im Niederschlag verloren gehen könne, sondern hielt mein Gemüth für die Beobachtung ganz frei. Die vereinigten Filtrate auf dem Wasserbad erwärmt bildeten ein leicht absetzbares Pulver, dessen Menge desto grösser wurde je länger das Erwärmen dauerte. Nach und nach bildeten sich viele Gramme desselben, die abfiltrirt und gewaschen wurden. Bei einiger Untersuchung stellte sich heraus, dass der Absatz aus überbasischem Oxychlorid bestand $\left(\mathrm{PbCl}_{2}+6 \mathrm{PbO}+\mathrm{xH}_{2} \mathrm{O}\right)$. Nach mehrmaligem Auskochen mit Wasser, war es ganz unlöslich in Wasser, vollständig löslich in kaustischem Kali, in Salpeter- und Essigsäure. Mit Salpetersäure bildete es keine Schwefelsäure, mit kohlensaurem Kali gekocht gab es kein Schwefelcyan an dieses ab. Für sich erhitzt verlor es plötzlich Wasser und verwandelte sich in das schönste "Kasseler Gelb“. Die Abkochung von diesem Niederschlag (welche Gscheidlen in seinem Experiment übrigens nicht berücksichtigt hatte) musste somit alles Schwefelcyanblei enthalten, welches sich etwa aus dem Filtrat von der Bleifällung abgesetzt haben konnte. Sie wurde auf ein kleines Volum abgedampft, setzte aber nur amorphes Pulver, keine Krystalle $a b$. Flüssigkeit and Pulver wurden jedes für sich mit kohlensaurem Kali zersetzt, und die alkalischen stark gelben Filtrate auf Schwefelcyan geprüft. Und siehe da! Sowohl Eisenchlorid in Gegenwart eines Ueberschusses von Salzsäure gab tiefe bräunliche Röthung, als auch Jodsäure und Stärke blaue Färbung. Ich destillirte nun die ganze Flüssigkeit mit Phosphorsäure auf die Hälfte $a b$; allein im Destillat war keine Spur von Reaction a uf Schwefelcyan zu bemerken; die jetzt braune, mit Zersetzungsproducten von Harnfarbstoff durchsetzte Flüssigkeit gab die Reaction mit Jodsäure noch lebhafter als vorher.

Somit enthielt auch diese Abkochung kein Schwefelcyan, und ich wandte mich daher an den mit dem Bleizucker hervorgebrachten Hauptniederschlag. Er wurde mit drei Liter Wasser gewaschen und das Filtrat abgedampft. Der gebildete Absatz sowohl als das Filtrat wirrden auf Schwefelcyan geprüft, aber ohne Erfolg.

Endlich destillirte ich auch den vierten Theil des Hauptextracts, welches das „Kasseler Gelb" geliefert hatte, entsprechend 4.31 Liter Harn, mit Ueberschuss von Phosphorsäure, und erhielt in keinem 
Theil des in drei Portionen aufgefangenen Destillats eine Spur von Schwefelcyansäure.

Beweis, dass der im Harn enthaltene schwefelhaltige Körper, welcher mit Salzsäure und Zink Hydrothion liefert, nicht Schwefelcyan ist.

Dieser Körper, dessen einzige bis jetzt bekannte Reaction zuerst von Schönbein beobachtet wurde, wird durch Bleizucker beinahe vollständig entfernt. Aus dem Bleiniederschlag erhält man ihn leicht wieder in Lösung durch Behandlung mit kohlensaurem Kali in der Wärme. Befreit man diese Lösung durch Baryt von allẹ Schwefelsäure und destillirt sie mit einem Ueberschuss von Phosphorsäure, so erhält $m a n$ in keinem Stadium des Destillirens auch nur eine Spur von Schwefelcyansäure oder schwefliger Sạare. Fährt man mit dem Destilliren fort, bis die Mischung syrupdick ist, so ist beinahe aller Harnfarbstoff zersetzt, und aus den gebildeten schwarzbraunen Harzen erhält man auf die von mir beschriebene Weise Uromelanin und Urogittin. Die stark gefärbte Flüssigkeit, mit Salzsäure und Zink behandelt, liefert Schwefelwasserstoff, und zwar scheinbar gerade so viel als vor der Destillation. Dabei entfärbt sie sich beinahe vollständig; dieselbe Flüssigkeit vor der Destillation mit Zink und Salzsäure behandelt, entfärbt sich zwar auch, aber nicht so vollständig als nach der Destillation. Vor wie nach der Destillation gibt sie mit Jodsäure Reduction zu Jod, hauptsächlich von Harnsäure herrührend. Aber auch das Urochrom scheint an dieser Reduction der Jodsäure zu Jod Theil zu nehmen. Der Schwefelkörper hat daher die folgenden weiteren Eigenschaften:

1) Er bildet eine Bleiverbindung, die in Wasser unlöslich ist.

2) Er ist nicht flüchtig, wenn er mit einem grossen Ueberschuss von Phosphorsäure gekocht und bis zur Syrupdicke der Lösung eingedampft wird. $\mathrm{Er}$ ist daher nicht Schwefelcyansäure.

Dieses Experiment habe ich an 35 Liter Harn ausgeführt. Nach Ausfällung mit neutralem essigsaurem Blei (120 Ce. gesättigter Lösung auf jedes Liter Harn) worde das Filtrat mit basischem essigsaurem Blei ausgefällt ( $1 / 2$ Liter gesättigte Lösung auf jedes' Liter Filtrat). Das Filtrat wurde nun mit etwas mehr Bleilösung versetzt, mit Ammoniak alkalisch gemacht, und der dritte Niederschlag abfiltrirt. Von der elngedickten Lösung wurde kohlensaures Blei, worin auch 
Oxychlorid enthalten war, als vierter Niederschlag abfiltrirt. Aus der Lösung wurde alles Blei durch Kochen mit kohlensaurem Kăli entfernt (fünfter Niederschlag) und dieselbe dann konzentrirt. Auch in ihr liess sich keine Schwefelcyansäure nachweisen.

Ich bin nun gerne bereit anzuerkennen, dass Fxperimente mit negativem Resultat gegenüber solchen mit widersprechendem positiven Resultat nur einen sehr beschränkten Werth haben. Ich muss aber, die gegenwärtige Discussion betreffend in Abrede stellen, dass G s c heidlen irgend ein zwingendes positives Resultat zu Tage gefördert hat. Denn 1) durch meine Experimente, betreffend die Eigenschaften des Schwefelcyanblei's, fällt der ganze Process, den Gscheidlen zur Isolirung dieses Körpers aus Harn zur Anwendung brachte, auch ohwe mein negatives Resultat der Wiederholung seines Experiments. In der That könnte man demnach an Gscheidlen die Anforderung stellen, zu erklären, wie er es angestellt habe, vermittelst eines unmöglichen Processes ein „Präparat von grosser Reinheit" zu gewinnen. 2) Durch mein Experiment, den Schönbein'schen Schwefelkörper betreffend, fällt die Stütze, welche er aus diesem machen zu können glaubte. 3) Die Reaction mit Eisenchlorid, deren sich Gs cheidlen zum Nachweis der Schwefelcyansäure auch in stark gefärbten Harnextracten bedient, hat keinen diagnostischen Werth, denn sie kommt nicht nur einer Anzahl von Säuren zu, die im Harn enthalten sind, sondern ist auch eine Eigenthümlichkeit des Harnfarbstoffs, und die dunkelrothe Farbe, welche Urochrom und Eisenchlorid miteinander bilden, wird durch Salzsäure nur etwas gemindert, aber nicht entfernt. Sogar das Urogittin in alkoholischer Lösung gibt mit Salzsäure und Eisenchlorid dunkelrothe Färbung, die von der durch Schwefelcyansäure bewirkten nicht zu unterscheiden ist. Der Harnfarbstoff gibt auch die Reaction mit Jodsäure, doch langsamer als Schwefelcyan- oder Harnsäure. Er verhält sich dabei wie manche Alkaloide, und ist diess ein Grund mehr, neben den zahlreichen bereits von mir angegebenen, ihn für ein Alkaloid zu halten.

Nach alledem muss ich behaupten, dass bis jetzt die 'Gegenwart von Schwefelcyansäure im Harn von Niemand bewiesen worden ist. Als Beweis könnte nur gelten die Darstellung der Schwefelcyansäure in Substanz in krystallisirter Verbindung, und der analytische Nachweis der richtigen Verhältnisse aller darin vorhandenen Elemente; dabei wäre zu verlangen, dass die Säure wenigstens einmal 
56 J. L. W. Thudichutin: Wiederholung des Versuchs von Gscheidlen ete.

destillirt worden sei, und dass sie die characteristischen Reactionen liefere.

Der Gedanke, dass, weil Schwefelcyansäure im Speichel enthalten ist, sie auch in den Harn übergehen müsse, enthält ein Element der Wahrscheinlichkeit, das zur Forschung einladet. Allein wiederum ist es wahrscheinlich, dass die Säure chemischen Zwecken des Körpers diene, und darin entweder verbunden, oder verändert, oder gar durch vollständige Oxydation zerstört werde. Die weitere Untersuchung dieser Frage wird aus obiger Diskussion wohl einigen Nutzen zu ziehen im Stande sein. Sie wird sich aber auch an dem Beispiel des Herrn Gscheidlen eine Warnung nehmen, und solche betrübende Verluste an Zeit und Mühe vermeiden. Welchen Werth haben jetzt all die Argumente, quantitativen Schätzungen, Experimente an Thieren, alle die mühsamen Versuche zur Führung eines indirecten Beweises, der nur direct geführt werden kann? Is ist schmerzlich, dass die Frage nur eine Antwort zulässt - Keinen. 